Article

\title{
Combination Effect of Antituberculosis Drugs and Ethanolic Extract of Selected Medicinal Plants against Multi-Drug Resistant Mycobacterium tuberculosis Isolates
}

\author{
Prabasiwi Nur Fauziyah *, Elin Yulinah Sukandar and Dhyan Kusuma Ayuningtyas \\ School of Pharmacy, Bandung Institute of Technology, Bandung, West Java 40132, Indonesia; \\ elin@fa.itb.ac.id (E.Y.S.); dhyankusumaayuningtyas@gmail.com (D.K.A.) \\ * Correspondence: nprabasiwi@yahoo.com; Tel.: +62-22-250-4852 \\ Academic Editor: Gernot Eller \\ Received: 22 December 2016; Accepted: 15 March 2017; Published: 20 March 2017
}

\begin{abstract}
Adverse drug reaction and resistance to antituberculosis drugs remain the causes of tuberculosis therapeutic failure. This research aimed to find the combination effect of standard antituberculosis drugs with Hibiscus sabdariffa L., Kaempferia galanga L., and Piper crocatum N.E. $\mathrm{Br}$ against multi-drug resistant (MDR) Mycobacterium tuberculosis isolates. Two MDR strains (i.e., isoniazid/ethambutol resistant and rifampicin/streptomycin resistant) of $M$. tuberculosis were inoculated in Löwenstein-Jensen medium containing a combination of standard antituberculosis drugs and ethanolic extracts of $H$. sabdariffa calyces, $K$. galanga rhizomes, and P. crocatum leaves using various concentration combinations of drug and extract. The colony numbers were observed for 8 weeks. The effect of the combination was analyzed using the proportion method which was calculated by the mean percentage of inhibition reduction in a number of colonies on drug-extract containing medium compared to extract-free control medium. The results showed that all three plant extracts achieved good combination effects with rifampicin against the rifampicin/streptomycin resistant strain. Antagonistic effects were, however, observed with streptomycin, ethambutol and isoniazid, therefore calling for caution when using these plants in combination with antituberculosis treatment.
\end{abstract}

Keywords: combination; Hibiscus sabdariffa; Kaempferia galanga; Piper crocatum; antituberculosis drug

\section{Introduction}

Tuberculosis (TB) remains one of the deadliest communicable diseases globally, including in Indonesia. The World Health Organization (WHO) estimated that globally in 2013, there were approximately 9 million people suffering from tuberculosis and 1.5 million died from tuberculosis, 360,000 of whom were TB-human immunodeficiency virus (HIV) positive. About $56 \%$ of TB patients in the world were in the South East Asia region and West Pacific region.

Although strategies to eradicate tuberculosis have been applied worldwide, tuberculosis eradication is still facing many problems and more development in strategic therapy is required. Increasing cases of multi-drug resistant tuberculosis (MDR-TB) and poor achievement in therapeutic goals are the major concerns. The proportion of new MDR-TB cases was 3.5\% of all new tuberculosis cases globally and the number of MDR-TB patients increased three-fold in 2013. It was estimated that 6800 new cases of MDR-TB were developed in Indonesia and more than 55\% of MDR-TB patients were not correctly diagnosed or treated [1]. The length of therapy also remains a burden. Tuberculosis patients need two months of intensive phase therapy followed by four months of maintenance phase therapy. Many patients did not achieve therapeutic the therapeutic goals due to side effects during therapy and non-compliance with the regimen of therapy [2]. 
The need to accelerate the eradication of tuberculosis globally requires more inventions and developments. Standard antituberculosis drugs used today were introduced 40 or more years ago [3]. The world urgently needs new regimens that can shorten and simplify the treatment, that are active against multi-drug strains and can be administrated with antiretroviral drugs to improve therapeutic outcomes.

Medicinal plants offer a big chance to meet the needs of new antituberculosis regimens. A large number of plant species have been investigated for their activity against Mycobacterium tuberculosis. More recently, several studies have reported that native Indonesian plants that are traditionally used for respiratory diseases have specific antimycobacterial activity [4-6]. Nevertheless, using medicinal plants or natural products as a single agent to treat tuberculosis is not recommended by health professionals because of the rising threat of resistance to inadequate treatment. Besides that, there is no study reporting that a combination of antituberculosis drugs and medicinal plant extracts improve outcome. Therefore, this study aimed to demonstrate the activity of standard antituberculosis drugs combined with Hibiscus sabdariffa L., Kaempferia galanga L., and Piper crocatum N.E. Br against multi-drug resistant (MDR) M. tuberculosis isolates.

\section{Materials and Methods}

\subsection{Plant Collection}

H. sabdariffa L., K. galanga L., and P. crocatum N.E. Br used for this study were obtained from Manoko Botanical Garden, Lembang, Bandung, Indonesia and identified at School of Life Sciences and Technology, Bandung Institute of Technology. The dried calyces of H. sabdariffa L., dried rhizomes of K. galanga L., and dried leaves of P. crocatum N.E. Br were cut into small pieces and powdered mechanically and stored in a sealed container.

\subsection{Extraction}

Each dried powdered plant was extracted using the reflux method and ethanol as solvent. The solvent was replaced twice, every 3 hours from the solvent boiling time. The liquid ethanolic extracts obtained were filtered and concentrated using a rotary evaporator (Buchi Labortechnik AG, Postfach, Flawil, Switzerland) for approximately 3 weeks until no ethanol dropped into the solvent flask on the rotary evaporator. The extracts were further concentrated using a waterbath set at $80^{\circ} \mathrm{C}$. These two steps of concentration will eliminate the ethanol residue in the extracts. The concentrated extracts obtained were weighted and stored in an airtight container.

\subsection{Mycobacterium Strain}

This study used two isolated strains of multi-drug resistant M. tuberculosis, i.e., rifampicin/streptomycin resistant and isoniazid/ethambutol resistant. Mycobacterium isolates used for this study must be $2-4$ weeks old. The bacteria strains were provided by Department of Microbiology, Health Laboratory of West Java Province, Bandung, Indonesia. The drug-resistant strains were isolated and cultured from a patient with MDR TB, but the TB treatment history of the patient was unknown because the patient treatment history was at a different health facility.

\subsection{Preliminary Study}

The extracts were diluted using sterile water and incorporated to medium to attain concentrations of $50,100,250,500,750$, and $1000 \mu \mathrm{g} / \mathrm{mL}$. The results of this step were used to determine the extract concentration to be combined with antituberculosis drugs. Extract-free medium with bacteria was used as a positive control and extract-free medium without bacteria was used as a negative control. These extracts and controls were duplicated to increase data reliability. The previously prepared bacteria were inoculated to each medium. All samples were incubated at $37{ }^{\circ} \mathrm{C}$ for 8 weeks. The number of colonies was counted every week. 


\subsection{Drug-Extract Combination Assay}

The test was performed as an antimycobacterial activity assay using the Löwenstein-Jensen (LJ) proportion method with slight modification [7]. The standard extract concentration used in this method was $1000 \mu \mathrm{g} / \mathrm{mL}$ for H. sabdariffa and P. crocatum, and $500 \mu \mathrm{g} / \mathrm{mL}$ for K. galanga. The standard antituberculosis drug concentrations used in this method were $40 \mu \mathrm{g} / \mathrm{mL}, 4 \mu \mathrm{g} / \mathrm{mL}, 2 \mu \mathrm{g} / \mathrm{mL}$, and $0.2 \mu \mathrm{g} / \mathrm{mL}$ for rifampicin, streptomycin, ethambutol, and isoniazid, respectively. Two series of stock solution were made by diluting each extract and each antituberculosis standard drug with sterile distilled water. The concentrations of stock solution used were $30 \mathrm{mg} / \mathrm{mL}$ and $15 \mathrm{mg} / \mathrm{mL}$ for extract stock solutions and $120 \mu \mathrm{g} / \mathrm{mL}$ and $60 \mu \mathrm{g} / \mathrm{mL}$ for standard drug stock solutions. To make the 40:1000 combination of rifampicin and $H$. sabdariffa extract, $2 \mathrm{~mL}$ of $30 \mathrm{mg} / \mathrm{mL}$ extract stock solution and $20 \mathrm{~mL}$ of $120 \mu \mathrm{g} / \mathrm{mL}$ rifampicin stock solution were added to $38 \mathrm{~mL}$ of sterile LJ medium solution and shaken gently until homogenous. To make the 4:1000 combination of streptomycin and H. sabdariffa extract, $2 \mathrm{~mL}$ of $30 \mathrm{mg} / \mathrm{mL}$ extract stock solution and $2 \mathrm{~mL}$ of $120 \mu \mathrm{g} / \mathrm{mL}$ streptomycin stock solution were added to $56 \mathrm{~mL}$ of sterile LJ medium solution and shaken gently until homogenous. To make the 2:1000 combination of ethambutol and $H$. sabdariffa extract, $2 \mathrm{~mL}$ of $30 \mathrm{mg} / \mathrm{mL}$ extract stock solution and $1 \mathrm{~mL}$ of $120 \mu \mathrm{g} / \mathrm{mL}$ ethambutol stock solution were added to $57 \mathrm{~mL}$ of sterile LJ medium solution and shaken gently until homogenous. To make the 0.2:1000 combination of isoniazid and H. sabdariffa extract, $2 \mathrm{~mL}$ of $30 \mathrm{mg} / \mathrm{mL}$ extract stock solution and $0.10 \mathrm{~mL}$ of $120 \mu \mathrm{g} / \mathrm{mL}$ ethambutol stock solution were added to $57.90 \mathrm{~mL}$ of sterile LJ medium solution and shaken gently until homogenous. The same procedure was repeated to make the combination of P. crocatum extract-standard drugs. To make the combination of K. galanga extract and standard drugs, the procedure was similar to the previous procedure but the extract volume stock added was $1 \mathrm{~mL}$ and the media volume was adjusted to $60 \mathrm{~mL}$ total volume. The procedure to make the combination with a lower concentration of extracts and drugs was similar to the previous combination procedure, but used the $15 \mathrm{mg} / \mathrm{mL}$ extract stock solutions and $60 \mu \mathrm{g} / \mathrm{mL}$ standard drug stock solutions. Tables 1 and 2 summarize this preparation step. Drug-containing medium solution and drug-extract-free medium solution, used as controls, were also prepared at the same time.

Every $7 \mathrm{~mL}$ of each of extract-drug-medium solution was pipetted and dispensed into a sterile McCartney bottle. These bottles were arranged on a particular rack at $30^{\circ}$ lean-position and then incubated at $85^{\circ} \mathrm{C}$ for $45 \mathrm{~min}$ to coagulate. After incubation time, the LJ-medium bottles were cooled down to room temperature for $24 \mathrm{~h}$ before being inoculated with $M$. tuberculosis isolates.

Two strains of MDR M. tuberculosis sub-culture isolates were suspended and diluted into $10^{-3}$ and $10^{-5} \mathrm{McF}$ arland using 5-fold dilution step methods from a $1.0 \mathrm{McF}$ arland standard dilution. An amount of $100 \mu \mathrm{L}$ of rifampicin/streptomycin resistant strain mycobacterial suspension of $10^{-3} \mathrm{McFarland}$ dilution was inoculated to each drug-extract containing medium bottle and drug-containing medium bottle, except the negative control medium bottle. The same procedure was repeated to the isoniazid/ethambutol resistant strain and $10^{-5} \mathrm{McFarland}$ concentration. After inoculation, all the medium bottles were incubated at $37^{\circ} \mathrm{C}$. The number of colonies of MDR M. tuberculosis was observed and counted every week for 8 weeks. 
Table 1. Summary of the preparation to make the Hibiscus sabdariffa and Piper crocatum combination with standard antituberculosis drugs.

\begin{tabular}{|c|c|c|c|c|c|c|c|}
\hline Standard Drug & $\begin{array}{c}\text { Standard Drug } \\
\text { Stock Concentration } \\
(\mu \mathrm{g} / \mathrm{mL})\end{array}$ & $\begin{array}{l}\text { Drug Stock } \\
\text { Volume (mL) }\end{array}$ & $\begin{array}{c}\text { Extract Stock } \\
\text { Concentration } \\
(\mu \mathrm{g} / \mathrm{mL})\end{array}$ & $\begin{array}{l}\text { Extract Stock } \\
\text { Volume (mL) }\end{array}$ & Media Volume (mL) & Total Volume (mL) & $\begin{array}{l}\text { Final Drug:Extract } \\
\text { Ratio Concentration }\end{array}$ \\
\hline Rifampicin & 120 & 20.00 & 30,000 & 2.000 & 38.00 & 60 & 40:1000 \\
\hline Isoniazid & 120 & 0.10 & 30,000 & 2.000 & 57.90 & 60 & $0.2: 1000$ \\
\hline Ethambutol & 120 & 1.00 & 30,000 & 2.000 & 57.00 & 60 & 2:1000 \\
\hline Streptomycin & 120 & 2.00 & 30,000 & 2.000 & 56.00 & 60 & $4: 1000$ \\
\hline Rifampicin & 60 & 20.00 & 15,000 & 2.000 & 38.00 & 60 & $20: 500$ \\
\hline Isoniazid & 60 & 0.10 & 15,000 & 2.000 & 57.90 & 60 & $0.1: 500$ \\
\hline Ethambutol & 60 & 1.00 & 15,000 & 2.000 & 57.00 & 60 & $1: 500$ \\
\hline Streptomycin & 60 & 2.00 & 15,000 & 2.000 & 56.00 & 60 & 2:500 \\
\hline
\end{tabular}

Table 2. Summary of the preparation to make the Kaempferia galanga combination with standard antituberculosis drugs.

\begin{tabular}{|c|c|c|c|c|c|c|c|}
\hline Standard Drug & $\begin{array}{c}\text { Standard Drug } \\
\text { Stock Concentration } \\
(\mu \mathrm{g} / \mathrm{mL})\end{array}$ & $\begin{array}{l}\text { Drug Stock } \\
\text { Volume (mL) }\end{array}$ & $\begin{array}{c}\text { Extract Stock } \\
\text { Concentration } \\
(\mu \mathrm{g} / \mathrm{mL})\end{array}$ & $\begin{array}{l}\text { Extract Stock } \\
\text { Volume (mL) }\end{array}$ & Media Volume (mL) & Total Volume (mL) & $\begin{array}{l}\text { Final Drug:Extract } \\
\text { Ratio Concentration }\end{array}$ \\
\hline Rifampicin & 120 & 20.00 & 30,000 & 1.00 & 39.00 & 60 & $40: 500$ \\
\hline Isoniazid & 120 & 0.10 & 30,000 & 1.00 & 58.90 & 60 & $0.2: 500$ \\
\hline Ethambutol & 120 & 1.00 & 30,000 & 1.00 & 58.00 & 60 & $2: 500$ \\
\hline Streptomycin & 120 & 2.00 & 30,000 & 1.00 & 57.00 & 60 & 4:500 \\
\hline Rifampicin & 60 & 20.00 & 15,000 & 1.00 & 39.00 & 60 & $20: 250$ \\
\hline Isoniazid & 60 & 0.10 & 15,000 & 1.00 & 58.90 & 60 & $0.1: 250$ \\
\hline Ethambutol & 60 & 1.00 & 15,000 & 1.00 & 58.00 & 60 & $1: 250$ \\
\hline Streptomycin & 60 & 2.00 & 15,000 & 1.00 & 57.00 & 60 & $2: 250$ \\
\hline
\end{tabular}




\section{Results}

As the study was performed as an antimycobacterial assay, the data collected were Mycobacterium colony counts on LJ medium for 8 weeks. The collected data were then processed using the proportion method which resulted in a percentage of inhibition as shown in Table 3 for the preliminary study and Table 4 for the drug-extract combination study.

Table 3. Percent of inhibition of various extract concentrations against multi-drug resistant (MDR) Mycobacterium tuberculosis isolates.

\begin{tabular}{|c|c|c|c|c|c|c|c|c|c|}
\hline \multirow{2}{*}{ Botanical Name } & \multirow{2}{*}{$\begin{array}{c}\text { Concentration } \\
(\mu \mathrm{g} / \mathrm{mL})\end{array}$} & \multicolumn{8}{|c|}{ Mycobacterium tuberculosis Strain } \\
\hline & & 1 & 2 & $\begin{array}{l}\text { Mean } \\
\text { CFU' }^{c}\end{array}$ & $\begin{array}{l}\text { Mean \% } \\
\text { Inhibition }\end{array}$ & 1 & 2 & $\begin{array}{l}\text { Mean } \\
\text { CFU }^{\mathrm{c}}\end{array}$ & $\begin{array}{l}\text { Mean \% } \\
\text { Inhibition }\end{array}$ \\
\hline Control (-) & - & 0 & 0 & $0 \pm 0$ & - & 0 & 0 & $0 \pm 0$ & - \\
\hline Control (+) & - & 390 & 176 & $283 \pm 107$ & - & 216 & 375 & $295 \pm 80$ & - \\
\hline Kaempferia galanga L. & $\begin{array}{c}50 \\
100 \\
250 \\
500 \\
750 \\
1000\end{array}$ & $\begin{array}{c}85 \\
62 \\
24 \\
6 \\
0 \\
0\end{array}$ & $\begin{array}{c}43 \\
33 \\
9 \\
0 \\
0 \\
0\end{array}$ & $\begin{array}{c}64 \pm 21 \\
47 \pm 15 \\
17 \pm 7 \\
3 \pm 3 \\
0 \pm 0 \\
0 \pm 0\end{array}$ & $\begin{array}{c}77 \pm 1 \\
83 \pm 1 \\
94 \pm 0 \\
99 \pm 1 \\
100 \pm 0 \\
100 \pm 0\end{array}$ & $\begin{array}{c}176 \\
129 \\
16 \\
0 \\
0 \\
0\end{array}$ & $\begin{array}{c}63 \\
115 \\
15 \\
0 \\
0 \\
0\end{array}$ & $\begin{array}{c}120 \pm 56 \\
122 \pm 7 \\
16 \pm 1 \\
0 \pm 0 \\
0 \pm 0 \\
0 \pm 0\end{array}$ & $\begin{array}{c}51 \pm 32 \\
55 \pm 14 \\
94 \pm 2 \\
100 \pm 0 \\
100 \pm 0 \\
100 \pm 0\end{array}$ \\
\hline
\end{tabular}

a Isoniazid-Ethambutol; ${ }^{\mathrm{b}}$ Rifampicin-Streptomycin; ${ }^{\mathrm{c}}$ Colony Forming Unit. 
Table 4. The percentage of inhibition for various combinations of antituberculosis drug and extract against MDR Mycobacterium tuberculosis isolates.

\begin{tabular}{|c|c|c|c|c|c|c|c|c|c|c|}
\hline \multirow{3}{*}{ Standard Drugs } & \multirow{3}{*}{ Extract } & \multirow{3}{*}{$\begin{array}{c}\text { Concentration in } \\
\text { Combination }(\mu \mathrm{g} / \mathrm{mL})\end{array}$} & \multicolumn{8}{|c|}{ Mycobacterium tuberculosis Strain } \\
\hline & & & \multicolumn{4}{|c|}{ HE Resistant } & \multicolumn{4}{|c|}{ RS Resistant } \\
\hline & & & 1 & 2 & Mean CFU & $\begin{array}{l}\text { Mean \% } \\
\text { Inhibition }\end{array}$ & 1 & 2 & Mean CFU & $\begin{array}{l}\text { Mean \% } \\
\text { Inhibition }\end{array}$ \\
\hline Control (+) & - & - & 128 & 188 & $158 \pm 30$ & - & 173 & 179 & $176 \pm 3$ & - \\
\hline \multirow{7}{*}{ Rifampicin } & - & - & 0 & 0 & 0 & $100 \pm 0$ & 148 & 118 & $133 \pm 15$ & $24 \pm 10$ \\
\hline & H. sabdariffa & 40:1000 & 0 & 0 & 0 & $100 \pm 0$ & 0 & 0 & 0 & $100 \pm 0$ \\
\hline & P. crocatum & 40:1000 & 0 & 0 & 0 & $100 \pm 0$ & 0 & 0 & 0 & $100 \pm 0$ \\
\hline & K. galanga & 40:500 & 0 & 0 & 0 & $100 \pm 0$ & 0 & 0 & 0 & $100 \pm 0$ \\
\hline & H. sabdariffa & 20:500 & 0 & 0 & 0 & $100 \pm 0$ & 0 & 0 & 0 & $100 \pm 0$ \\
\hline & P. crocatum & 20:500 & 0 & 0 & 0 & $100 \pm 0$ & 0 & 0 & 0 & $100 \pm 0$ \\
\hline & K. galanga & $20: 250$ & 0 & 0 & 0 & $100 \pm 0$ & 0 & 0 & 0 & $100 \pm 0$ \\
\hline \multirow{7}{*}{ Streptomycin } & - & & 0 & 0 & 0 & $100 \pm 0$ & 128 & 222 & $175 \pm 47$ & $1 \pm 1$ \\
\hline & H. sabdariffa & 4:1000 & 0 & 0 & 0 & $100 \pm 0$ & 141 & 129 & $135 \pm 6$ & $23 \pm 5$ \\
\hline & P. crocatum & $4: 1000$ & 0 & 0 & 0 & $100 \pm 0$ & 127 & 117 & $122 \pm 5$ & $31 \pm 4$ \\
\hline & K. galanga & 4:500 & 0 & 0 & 0 & $100 \pm 0$ & 98 & 58 & $78 \pm 20$ & $55 \pm 12$ \\
\hline & H. sabdariffa & $2: 500$ & 0 & 0 & 0 & $100 \pm 0$ & 121 & 103 & $112 \pm 9$ & $36 \pm 6$ \\
\hline & P. crocatum & 2:500 & 0 & 0 & 0 & $100 \pm 0$ & 79 & 79 & $79 \pm 0$ & $55 \pm 1$ \\
\hline & K. galanga & 2:250 & 0 & 0 & 0 & $100 \pm 0$ & 52 & 124 & $88 \pm 36$ & $50 \pm 20$ \\
\hline \multirow{7}{*}{ Ethambutol } & - & - & 181 & 130 & $156 \pm 26$ & $1 \pm 3$ & 0 & 0 & 0 & $100 \pm 0$ \\
\hline & H. sabdariffa & $2: 1000$ & 123 & 121 & $122 \pm 1$ & $20 \pm 16$ & 0 & 0 & 0 & $100 \pm 0$ \\
\hline & P. crocatum & $2: 1000$ & 88 & 88 & $88 \pm 0$ & $42 \pm 11$ & 0 & 0 & 0 & $100 \pm 0$ \\
\hline & K. galanga & $2: 500$ & 48 & 17 & $33 \pm 15$ & $76 \pm 14$ & 0 & 0 & 0 & $100 \pm 0$ \\
\hline & H. sabdariffa & 1:500 & 130 & 26 & $78 \pm 52$ & $55 \pm 24$ & 0 & 0 & 0 & $100 \pm 0$ \\
\hline & P. crocatum & 1:500 & 98 & 93 & $96 \pm 3$ & $37 \pm 14$ & 0 & 0 & 0 & $100 \pm 0$ \\
\hline & K. galanga & $1: 250$ & 140 & 86 & $113 \pm 7$ & $29 \pm 4$ & 0 & 0 & 0 & $100 \pm 0$ \\
\hline \multirow{7}{*}{ Isoniazid } & - & - & 223 & 181 & $202 \pm 21$ & $0 \pm 0$ & 0 & 0 & 0 & $100 \pm 0$ \\
\hline & H. sabdariffa & $0.2: 1000$ & 133 & 137 & $135 \pm 2$ & $15 \pm 12$ & 0 & 0 & 0 & $100 \pm 0$ \\
\hline & P. crocatum & $0.2: 1000$ & 109 & 103 & $106 \pm 3$ & $30 \pm 15$ & 0 & 0 & 0 & $100 \pm 0$ \\
\hline & K. galanga & $0.2: 500$ & 74 & 84 & $79 \pm 5$ & $50 \pm 7$ & 0 & 0 & 0 & $100 \pm 0$ \\
\hline & H. sabdariffa & $0.1: 500$ & 140 & 129 & $135 \pm 5$ & $20 \pm 11$ & 0 & 0 & 0 & $100 \pm 0$ \\
\hline & P. crocatum & $0.1: 500$ & 101 & 109 & $105 \pm 4$ & $32 \pm 10$ & 0 & 0 & 0 & $100 \pm 0$ \\
\hline & K. galanga & $0.1: 250$ & 80 & 84 & $82 \pm 2$ & $46 \pm 9$ & 0 & 0 & 0 & $100 \pm 0$ \\
\hline
\end{tabular}


From the preliminary study, the inhibition of $M$. tuberculosis growth for all the medicinal plants used was more than $70 \% \pm 0.0 \%$, even at the lowest concentration. A concentration of $500 \mu \mathrm{g} / \mathrm{mL}$ was used as the standard concentration of $K$. galanga extract for the combination study because it was the lowest concentration of $K$. galanga giving $100 \%$ inhibition. A concentration of $1000 \mu \mathrm{g} / \mathrm{mL}$ was used as the standard concentration of $H$. sabdariffa and P. crocatum extract for the combination study because it was the highest concentration giving $M$. tuberculosis growth inhibition; the total inhibition $(100 \%)$ could not be met by any of the extract concentrations used. Although the results did not follow a dose-response relationship, choosing $1000 \mu \mathrm{g} / \mathrm{mL}$ as the standard concentration for $H$. sabdariffa and P. crocatum was thought to be the safest way to avoid inadequate inhibition activity in the combination study.

The results of this study showed that, for the rifampicin/streptomycin resistant strain, an additive effect was obtained when combining rifampicin with all three extracts. In particular, P. crocatum showed the highest increase in the percentage of inhibition, rising from $44 \%$ to $100 \%$ within the combination, even at the lower dose of $500 \mu \mathrm{g} / \mathrm{mL}$. Regarding the other antibiotics however, a decrease in the potency was observed, particularly for the combination with K. galanga. Indeed, the extract alone displayed $100 \%$ growth inhibition at $500 \mu \mathrm{g} / \mathrm{mL}$, while its combination with streptomycin, ethambutol and isoniazid yielded only $55 \%, 76 \%$ and $50 \%$ inhibition, respectively.

\section{Discussion}

Current tuberculosis treatment is facing major problems such as complexity and lengthy treatment duration. Adverse reactions to antituberculosis drugs may lead to non-adherence to treatment, causing poor outcomes and also therapeutic failure [8]. Another major concern is the increasing incidence of MDR tuberculosis, not only to the first-line antituberculosis drugs isoniazid and rifampicin, but also to the second-line drugs that are now becoming more common. Strengthening current tuberculosis treatment and discovering new antituberculosis drugs are required to overcome the challenges and to reach the WHO 2035 goal of ending the global tuberculosis epidemic $[1,8,9]$. The plants selected in this study are all used in Indonesian traditional medicine to treat respiratory disorders and have also been studied for their activity against $M$. tuberculosis.

In the present work, all of the selected medicinal plants used gave good combination effects with rifampicin, as compared to the drug used alone. The presence of the extract of three selected medicinal plants on LJ medium along with the antituberculosis drug could increase antimycobacterial activity against the rifampicin/streptomycin clinical isolates. However, K. galanga, P. crocatum, and H. sabdariffa had antagonistic effects with streptomycin, ethambutol and isoniazid. This was particularly apparent for K. galanga, which was able to fully inhibit the growth of both drug-resistant isolates alone, but lost this capacity when combined with antituberculosis drugs.

This study is the first to report on the combination effect of $K$. galanga, P. crocatum, and H. sabdariffa with standard antituberculosis drugs since previous studies have only investigated their antimycobacterial activity as a single agent. A study in India showed that Ethyl $p$-Methoxycinnamate (EPMC) isolated from K. galanga inhibited the MDR strain of M. tuberculosis. Ethyl cinnamate and EPMC were the major and vital constituents in the K. galanga extract, suspected to have antimycobacterial activity besides its larvacidal, nematicidal, anti-oxidant, antimicrobial, antineoplastic, and anti-inflammatory activity [10,11]. EPMC seems to be leading molecule to develop a new potent antituberculosis drug. In our study, it is still unknown whether the antimycobacterial mechanism of EPMC has the same molecule target or same mechanism of action as the standard antituberculosis drug.

Our results were in agreement with a previous in vitro and in vivo study using ethanolic extract of $P$. crocatum as an antimycobacterial agent, which revealed that exposure of the P. crocatum ethanolic extract can decrease the $M$. tuberculosis level both in vitro and in vivo [4]. The phytochemicals contained in P. crocatum were alkaloids, flavonoid, glycoside, saponin, tannin, and triterpenoid [12]. There were only limited studies about $P$. crocatum, its chemical constituents and activity as an antibacterial agent. None of those studies isolated the phytochemical compound of P. crocatum and investigated its activity 
against $M$. tuberculosis. Cell wall destruction was predicted as the mechanism of action of $P$. crocatum against $M$. tuberculosis. An observation under transmission electron microscope showed damage on the cell wall of M. tuberculosis after exposure to ethanolic extract of P. crocatum [4].

Our current finding on the combination effect of $H$. sabdariffa was also consistent with a previous study which showed that extract of $H$. sabdariffa inhibited the MDR strain of M. tuberculosis [5]. Constituents such as organic acid (hibiscus acid, hibiscus acid glucoside, hydroxycitric acid), anthocyanins (delphinidin-3-sambubioside, cyanidin-3-sambubioside), and flavonoids and phenolic acid (gallic acid, quercetin, myricetin, kaempferol, protocatechuic acid, etc.) were the main phytochemical compounds of $H$. sabadariffa related to its activity $[13,14]$. The exact mechanism of action against $M$. tuberculosis is not fully understood. An increase in plasma membrane permeability following inhibition of various cellular processes, leading to ion leakage, was predicted as the antibacterial mechanism of action of $H$. sabdariffa [15].

\section{Conclusions}

The results of our study indicated that K. galanga, P. crocatum, and H. sabdariffa gave good combination effects with rifampicin to combat the rifampicin/streptomycin resistant $M$. tuberculosis strain. However, an antagonistic effect was shown when all of the three extracts were combined with streptomycin, ethambutol, and isoniazid. The main mechanism of action is still unclear and uncertain as further studies needed. Future studies need to address the main pharmacologically active compound as an antimycobacterial agent and the target of the antituberculosis active compound in order to support the in vitro study result. In vivo studies are also needed to observe their effectiveness in whole-organism systems including toxicity studies. Use of these medicinal plants as traditional remedies in combination with antituberculosis drugs should be done with caution as not all plants displayed good synergic combination effects.

Acknowledgments: The authors thank to Ministry of Finance of Republic of Indonesia for financial supports and to Health Laboratory Institute of West Java Province for providing the materials and facilities needed in this study.

Author Contributions: P.N.F., E.Y.S., and D.K.A. conceived and designed the experiments; P.N.F. performed the experiments; D.K.A. contributed analysis tools; P.N.F. wrote the paper.

Conflicts of Interest: The authors declare no conflict of interest.

\section{References}

1. WHO. Global Tuberculosis Report; WHO Press: Geneva, Sweden, 2014; pp. 13-15.

2. Center of Data and Information of Ministry of Health of Republic of Indonesia. Tuberkulosis: Temukan, Obati Sampai Sembuh; Center of Data and Information Press: Jakarta, Indonesia, 2015; pp. 2-7.

3. Brennan, J.P.; Young, D.B.; Robertson, B.D. Handbook of Antituberculosis Agents; Elsevier: New York, NY, USA, 2008; pp. 85-170.

4. Rachmawaty, F.J. Antimycobacterial Activity of Ethanolic Extract and Essential oil of Red Betel Leaves (Piper crocatum) against Mycobacterium tuberculosis in Vitro and in Vivo. Ph.D. Thesis, Faculty of Medicine of Gadjah Mada University, Yogyakarta, Indonesia, 2014.

5. Rostinawati, T. Antibacterial Activity of Ethanolic Extract and Water Extract of Roselle Petals (Hibiscus sabdariffa L.) against Mycobacterium tuberculosis Labkes-026 (MDR) Strain and Mycobacterium tuberculosis H37Rv Strain in Vitro. Master's Thesis, Faculty of Pharmacy Padjadjaran University, Bandung, Indonesia, 1 March 2008.

6. Lakshmanan, D.; Werngren, J.; Jose, L.; Suja, K.P.; Nair, M.S.; Varma, R.L.; Mundayoor, S.; Hoffner, S.; Kumar, R.A. Ethyl- $p$-methoxycinnamate isolated from a traditional anti-tuberculosis medicinal herb inhibits drug resistant strains of Mycobacterium tuberculosis in vitro. Fitoterapia 2011, 82, 757-761. [CrossRef] [PubMed]

7. Gupta, R.; Thakur, B.; Singh, P.; Singh, H.B.; Sharma, V.D.; Katoch, V.M.; Chauhan, S.V. Anti-tuberculosis activity of selected medicinal plants against multi-drug resistant Mycobacterium tuberculosis isolates. Indian J. Med. Res. 2010, 131, 809-813. [PubMed] 
8. Boogard, J.V.D.; Kibiki, G.S.; Kisanga, E.R.; Boeree, M.J.; Aarnoutse, R.E. Minireview: New drugs against tuberculosis: problems, progress, and evaluation of agents in clinical development. Antimicrob. Agents Chemother. 2009, 53, 849-862. [CrossRef] [PubMed]

9. Lougheed, K.E.A.; Taylor, D.L.; Osborne, S.A; Bryans, J.S.; Buxton, R.S. New anti-tuberculosis agents amongst known drugs. Tuberculosis 2009, 89, 364-370. [CrossRef] [PubMed]

10. Umar, M.I.; Asmawi, M.Z.; Sadikun, A.; Altaf, R.; Iqbal, M.A. Phytochemistry and medicinal properties of Kaempferia galanga L. (Zingiberaceae) extracts. Afr. J. Pharm. Pharmacol. 2011, 5, 1638-1647. [CrossRef]

11. Umar, M.I.; Asmawi, M.Z.; Sadikun, A.; Majid, A.M.; Al-Suede, F.S.; Hassan, L.E.; Altaf, R.; Ahamed, M.B. Ethyl-p-methoxycinnamate isolated from Kaempferia galanga inhibits inflammation by suppressing interleukin-1, tumor necrosis factor- $\alpha$, and angiogenesis by blocking endothelial functions. Clinics 2014, 69, 134-144. [CrossRef]

12. Candrasari, A.; Romas, M.A.; Hasbi, M.; Astuti, O.R. Antimicrobial activity testing of ethanolic extract of red betel leaves (Piper crocatum Ruiz \& Pav.) against Staphylococcus aureus ATCC 6538, Escherichia coli ATCC 11229, and Candida albicans ATCC 10231 in vitro. Biomedika 2012, 4, 9-16.

13. Da-Costa-Rocha, I.; Bonnlaender, B.; Sievers, H.; Pischel, I.; Heinrich, M. Hibiscus sabdariffa L.-A phytochemical and pharmacological review. Food Chem. 2014, 165, 424-443. [CrossRef] [PubMed]

14. Sindi, H.A.; Marshall, L.J.; Morgan, M.R.A. Comparative chemical and biochemical analysis of extracts of Hibiscus sabdariffa. Food Chem. 2014, 164, 23-29. [CrossRef] [PubMed]

15. Fullerton, M.; Khatiwada, J.; Johnson, J.U.; Davis, S.; Williams, L.L. Determination of antimicrobial activity of sorrel (Hibiscus sabdariffa) on Escherichia coli O157:H7 isolated from food, veterinary, and clinical samples. J. Med. Food 2011, 14, 950-956. [CrossRef] [PubMed]

(c) 2017 by the authors. Licensee MDPI, Basel, Switzerland. This article is an open access article distributed under the terms and conditions of the Creative Commons Attribution (CC BY) license (http:/ / creativecommons.org/licenses/by/4.0/). 